\title{
Otosklerozlu hastalarda süperior semisirküler kanal dehissansının sıklığının araştırılması
}

\author{
Investigation of the frequency of superior semicircular canal dehiscence in patients with \\ otosclerosis
}

Pınar Çakmak

Gönderilme tarihi:16.08.2020

Kabul tarihi:22.09.2020

\section{Özet}

Amaç: Temporal kemik Bilgisayarlı Tomografi'de (BT) otoskleroz bulguları olan hastalarda süperior semisirküler kanal dehissansı(SSKD) sıklığını araştırmaktır.

Gereç ve yöntem: Temporal kemik BT'de otoskleroz bulgusu olan 43 (22 erkek, 21 kadın; ortalama yaş, $44 \pm 11$ yıl; dağııım, 20-71 yıl) hastanın 86 temporal kemik BT görüntüsü retrospektif olarak değerlendirildi. Bu BT görüntülerinde fenestral / retrofenestral tip otoskleroz bulgularının ve süperior semisirküler kanal dehissansının sıkıkları, yaş ve işitme kaybı tipleri ile karşılaştııılarak değerlendirildi.

Bulgular: 80 temporal kemikte fenestral tip $(n: 73, \% 84,8)$ ve retrofenestral tip $(n: 7, \% 8,1)$ otoskleroz tespit edildi. 86 temporal kemiğin 11 'inde $(\% 12,7)$ SSKD bulundu. Fenestral tip otoskleroz bulgusu tespit edilen 11 temporal kemikte eş zamanlı SSKD izlendi $(p=0,203)$. Retrofenestral tip otoskleroza sahip hastalar ile SSKD arasında istatistiksel olarak anlamlı farklııı saptanmadı $(p=0,588)$. 86 temporal kemikte $20-40$ yaş grupta, 40 yaş üstü gruba göre SSKD sıklığı anlamlı olarak fazla bulundu $(p=0,001)$.

Sonuç: Bu çalışmada otosklerozda SSKD sıklığı \%12,7 bulunmuş olup birlikteliğin sıklığının bilinmesi, otoskleroz nedeniyle opere olacak hastalarda yüksek çözünürlüklü temporal kemik BT'nin önemini arttırmaktadır.

Anahtar kelimeler: Otoskleroz, süperior semisirküler kanal dehissansı, bilgisayarlı tomografi, işitme kaybı.

Çakmak P. Otosklerozlu hastalarda süperior semisirküler kanal dehissansının sıkıı̆ının araştırıması. Pam Tıp Derg 2021;14:95-101.

\section{Abstract}

Purpose: To investigate the frequency of superior semicircular canal dehiscence (SSCD) in patients with signs of otosclerosis on temporal bone computed tomography (CT).

Materials and methods: The eighty six temporal bone CT images of 43 patients (22 male, 21 female; mean age, $44 \pm 11$ year-old; range, 20-71 year-old) with otosclerosis were retrospectively evaluated in Temporal bone CT. In these CT images, the frequency of fenestral / retrofenestral type otosclerosis findings and superior semicircular canal dehissance were compared with age and types of hearing loss.

Results: In 80 temporal bones, fenestral type (n:73, 84.8\%) and retrofenestral type ( $\mathrm{n}: 7,8.1 \%)$ otosclerosis were detected. SSCD was found in $11(12.7 \%)$ of 86 temporal bones. SSCD was detected in 11 temporal bones with signs of fenestral type otosclerosis $(p=0.203)$. There were no statistically significant differences between SSCD and patients with retrofenestral type otosclerosis $(p=0.588)$. In the evaluated 86 temporal bones, the frequency of superior semicircular canal dehissance was significantly higher in the 20-40 age group than the group which includes the patients over 40-year-old $(p=0.001)$.

Conclusion: In this study, the frequency of SSCD in otosclerosis was found to be $12.7 \%$ and knowing the frequency of association increases the importance of pre-operative high-resolution temporal bone $\mathrm{CT}$, especially in patients who will be operated due to otosclerosis.

Key words: Otosclerosis, superior semicircular canal dehiscence, computed tomography, hearing loss.

Cakmak P. Investigation of the frequency of superior semicircular canal dehiscence in patients with otosclerosis. PamMed J 2021;14:95-101. 


\section{Giriş}

Otoskleroz, otik kapsüldeki enkondral kemik yapının rezorpsiyonu, yeni kemik oluşumu ve vasküler proliferasyonla spongioz kemik adacıklarına dönüşümü ile karakterize otik kapsülün otozomal dominant otodistrofisidir [1-3]. Klinikte hastalar iletim tipi, sensorinöral (SNIK) veya mix tip işitme kaybı ve/veya tinnitus ile başvurmaktadır.

Bilgisayarlı tomografi (BT), antefenestral bölgede sıklıkla düşük yoğunluklu lezyonlar olarak tanımlanan otosklerotik odakların saptanmasında ana tanı araçlarından biridir ve otosklerozu, klinik olarak benzer bulgulara sahip olabilecek ossiküler zincir çıkığı ve superior semisirküler kanal dehisansı gibi diğer hastalıklardan ayırt etmede yardımcı olur $[4,5]$.

Komplike olmayan otoskleroz tanısı, özellikle iletim tipi işitme kaybı, normal timpanik membran, odyogram bulguları, aile öyküsü ve stapedial refleksler gibi karakteristik özellikleri ile klinik olarak koyulabilir. Bununla birlikte, klinik belirsizlik olduğunda ve özellikle bir SNIKK bileşeni olduğunda, tanı ve tedaviye rehberlik etmek için BT kullanılabilir. Şüpheli otoskleroz ortamında BT'nin potansiyel bir geniş tanı katkısı vardır. BT, ossiküler devamsızlık, ossiküler fiksasyon veya labirent anomalileri gibi otoskleroz bulgularına benzer odyolojik bulguları olan hastalarda alternatif patolojileri teşhis etmede, otosklerotik odakların yeri ve anatomik varyantların varlığının tespitinde, cerrahi seçenekler ve sonuçları üzerinde etki etmektedir [6, 7].

Süperior semisirküler kanal dehissansı (SSKD), orta kranial fossada dura boyunca süperior semisirküler kanalı kaplayan kemiğin yokluğu olarak tanımlanmaktadır. SSKD genellikle iletim tipi işitme kaybı da dahil olmak üzere sensorinöral veya mix tip işitsel semptomlara, vertigo, denge kaybı gibi vestibüler semptomlara ve hiperakuzi, otofoni, osilopsi gibi semptomlara neden olabilir [8].

Süperior semisirküler kanal dehissansı sadece vestibüler semptomlara yol açtığı gibi aynı zamanda işitsel semptomların baskın olduğu klinik durumada yol açabilmektedir. Majör vestibüler semptomların yokluğunda belirgin iletim tipi işitme kaybı ile başvuran, dolayısıyla kemikçik fiksasyonu benzeri otosklerozu taklit eden bir hasta alt grubu tanımlanmıştır [9, 10].
Otosklerozlu hastalarda operasyon öncesi SSKD tespit edilmez ise bu hastaların birçoğu stapedektomiden fayda görmemektedir.

$\mathrm{Bu}$ çalışmanın amacı Temporal kemik BT de otoskleroz tanısı almış hastalarda süperior semisirküler kanal dehissansı sıklığını araştırmaktır.

\section{Gereç ve yöntem}

\section{Çalışma grubu}

$\mathrm{Bu}$ çalışma, Pamukkale Üniversitesi Tıp Fakültesi Tıbbi Etik Kurulu'nun onayının alınması ile birlikte başlatılmıştır. Ocak 2018 ile Mart 2020 tarihleri arasında, merkezimize başvuran Temporal kemik BT tetkiklerinde otoskleroz saptanan hastaların süperior semsirküler kanal dehissansı açısından kontrastsız Temporal kemik BT tetkikleri retrospektif olarak değerlendirildi. Çalışmaya 18 yaş üzerindeki, konjenital anomalisi bulunmayan, nörojenik kaynaklı onkolojik hastalığı, metabolik kemik hastalığı bulunmayan tüm hastalar dahil edildi. Temporal kemik BT görüntülerinde otoskleroz bulgusu olan hastaların en sık şikayetleri işitme kaybı (iletim tipi, sensorinöral ve mix tip işitme kaybı), tinnitus ve vertigo idi. Çalışmaya 43 hasta dahil edildi. 43 hastadan (22 erkek, 21 kadın; ortalama yaş, 44ะ11 yıl; dağılım, 20-71 yıl) alınan 86 temporal kemik BT görüntüsü retrospektif olarak incelendi. Temporal BT görüntüleri 16 yıl tecrübeli radyolog tarafından değerlendirildi.

\section{Bilgisayarlı tomografi}

Kontrastsız Temporal Kemik BT incelemeleri multi-dedektör BT (Ingenuity 128, Philips Healthcare, USA and Brilliance 16, Philips Healthcare, Netherlands) tarayıcıdagerçekleştirildi. 128 dedektörlü BT için görüntüleme parametreleri: Tüp voltajı: 120 kV; kesit kalınlığı: 0,625 mm; Tüp akımı: $250 \mathrm{mAs}$; kolimasyon: 20x0,625 mm; matrix: 768x768; rotasyon zamanı: 0,4 saniye; FOV: 199,16 dedektörlü BT için görüntüleme parametreleri: Tüp voltajı: 120 kV; kesit kalınlığı: 0,8 mm; Tüp akımı: $150 \mathrm{mAs}$; kolimasyon: 16x0,75 mm; matrix: 512x512; rotasyon zamanı: 0,5 saniye; FOV: 250. BT görüntüleri iş istasyonunda değerlendirildi. 


\section{Görüntü analizi}

Seçilmiş hasta grubunda tüm hastaların kontrastsız Temporal Kemik BT'leri kemik pencerede değerlendirildi. Ham DICOM görüntüler iş istasyonuna aktarılarak, burada DICOM görüntüleyici ile rekonstrukte edilerek çok planlı kesitler (MPR, Multiplanar Rekonstruksiyonlar) oluşturuldu. Bu BT görüntülerinde fenestral ve retrofenestral tip otoskleroz bulguları ve süperior semisirküler kanal dehissansı değerlendirildi (Resim 1, Resim 2).

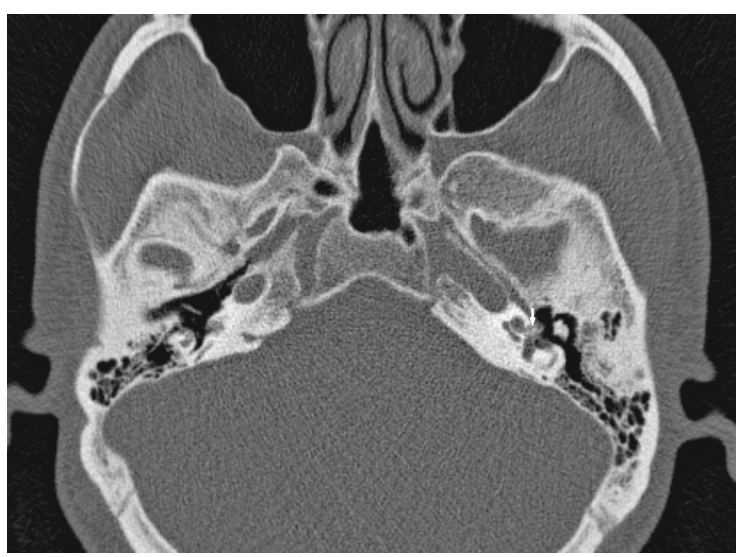

Resim 1a. Aksiyal temporal kemik BT görüntüde bilateral fenestral tip otosklerozu olan hastada solda oval pencere anteriorunda dansite azalması (beyaz ok)

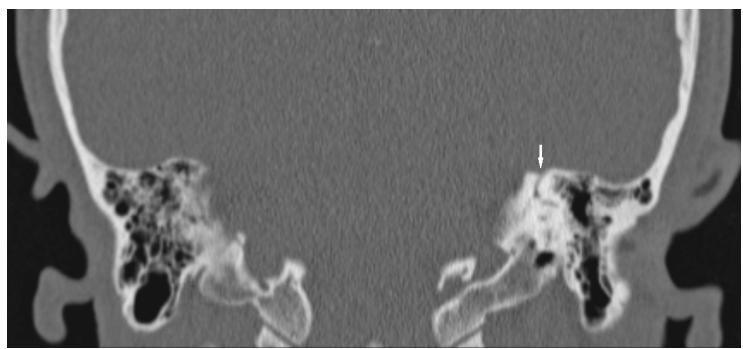

Resim 1b. Koronal temporal kemik BT görüntüde aynı hastada solda SSKD (beyaz ok)

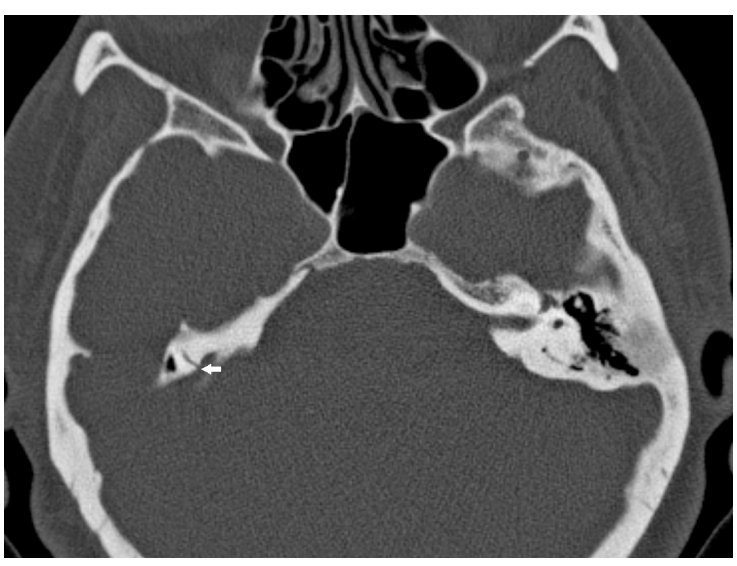

Resim 2a. Aksiyal temporal kemik BT görüntüde otosklerozlu hastada sağda SSKD (beyaz ok)

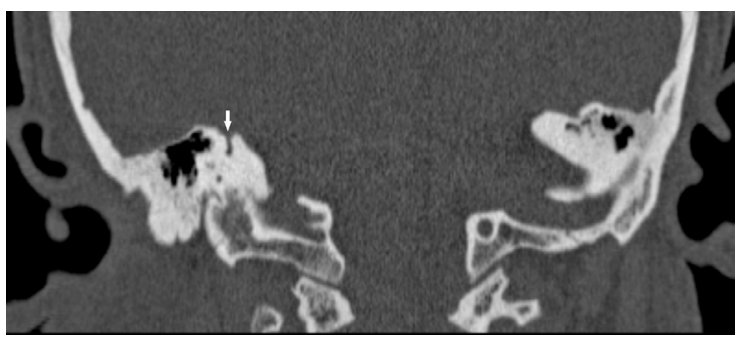

Resim 2b. Koronal temporal kemik BT görüntü sağda SSKD (beyaz ok)

\section{İstatistiksel analiz}

Veri analizi kişisel bilgisayarda istatistiksel yazılım (SPSS 21 for Windows, Chicago, IL) kullanılarak yapıldı.

İstatistiksel analizde tanımlayıcı istatistikler sürekli değişkenlerde ortalama \pm standart sapma biçiminde, kategorik değişkenlerde ise $\%$ şeklinde gösterildi. Kategorik değişkenler için Ki-kare testi, değişkenler arası ilişkilerde t-test kullanıldı. $p<0,05$ istatistiksel olarak anlamlı kabul edildi.

\section{Bulgular}

Hastaların 31 'inde $(\% 72,1)$ iletim tipi işitme kaybı, 5 'inde $(\% 11,6)$ sensorinöral işitme kaybı, 9'unda $(\% 20,9)$ mix tip işitme kaybı mevcuttu. $7(\% 16,3)$ hastada vertigo, $9(\% 20,9)$ hastada tinnitus şikayeti bulunmaktaydı (Tablo 1).

Hastalar 20-40 yaş, 40 yaş ve üzeri olarak iki gruba ayrıldı. Fenestral tip hastalarda yaş grupları arasında istatistiksel anlamlılığa bakıldığında, 20-40 yaş aralığında fenestral tip otoskleroz daha sık olarak izlendi $(p=0,013)$ (Tablo 2). Temporal kemik olarak değerlendirldiğinde de fenestral tip otoskleroz 
Tablo 1. Otosklerozlu hastalarda işitme kaybı tipleri

\begin{tabular}{llccc}
\hline İşitme kaybı tipi & Yok (n) & Sağ (n) & Sol (n) & Bilateral (n) \\
\hline İletim tipi işitme kaybı \%72,1 & $12(\% 27,9)$ & $7(\% 16,3)$ & $5(\% 11,6)$ & $19(\% 44,2)$ \\
Sensörinöral işitme kaybı \%11,6 & $38(\% 88,4)$ & $2(\% 4,6)$ & $0(\% 0)$ & $3(\% 7)$ \\
Mikst tip işitme kaybı \%20,9 & $34(\% 79,1)$ & $1(\% 2,3)$ & $4(\% 9,3)$ & $4(\% 9,3)$ \\
\hline
\end{tabular}

n: hasta sayısı

Tablo 2. Fenestral tip otosklerozlu hastaların yaş grubuna (20-40 yaş, 40 yaş üzeri) göre dağılımı

\begin{tabular}{llllll}
\hline \multirow{2}{*}{ Yaş grubu } & Yok $(\mathbf{n})$ & Sağ $(\mathbf{n})$ & Sol $(\mathbf{n})$ & Bilateral $(\mathbf{n})$ & $\boldsymbol{p}$ \\
\cline { 2 - 6 } & 0 & 0 & 1 & 21 & 0,013 \\
\hline $20-40$ yaş & 2 & 3 & 5 & 11 & \\
\hline
\end{tabular}

n: hasta sayısı

20-40 yaş aralığında anlamlı olarak yüksekdi $(p=0,001)$. Retrofenestral tip otoskleroz için yaş grupları ya da cinsiyet arasında istatistiksel olarak anlamlı farklılık saptanmadı.

Toplamda 43 hasta, 86 temporal kemik değerlendirildi. 86 temporal kemikte fenestral $(n: 73, \% 84,8)$ ve retrofenestral tip $(n: 7, \% 8,1)$ otoskleroz tespit edildi. 9 temporal kemikte otoskleroz bulgusu saptanmaz iken, 1 hastada solda fenestral, bilateral retrofenestral tip otoskleroz, 1 hastada bilateral fenestral ve retrofenestral otoskleroz (3 temporal kemikte) saptandı.
86 temporal kemik değerlendirildiğinde; 11 $(\% 12,7)$ temporal kemikte, 43 hastanın 7'sinde $(\% 16,2)$ süperior semisirküler kanal dehissansı izlendi. Fenestral tip otoskleroza sahip 11 kulakda süperior semisirküler kanal dehissansı saptandı $(p=0,203)$. Retrofenestral tip otoskleroza sahip hastalar ile SSKD arasında istatistiksel olarak anlamlı farklılık saptanmadı $(p=0,588)$ (Tablo 3$)$.

Otosklerozlu hastaların İletim tipi $(p=0,107)$ ve sensorinöral tip işitme kayıpları ile SSKD arası anlamlı farklılk saptanmadı.

86 temporal kemikte 20-40 yaş grupta, 40 yaş üstü gruba göre SSKD sıklığı anlamlı olarak fazla bulundu $(p=0,001)$.

Tablo 3. Otosklerozlu kulaklarda otoskleroz tipine göre SSKD birlikteliği

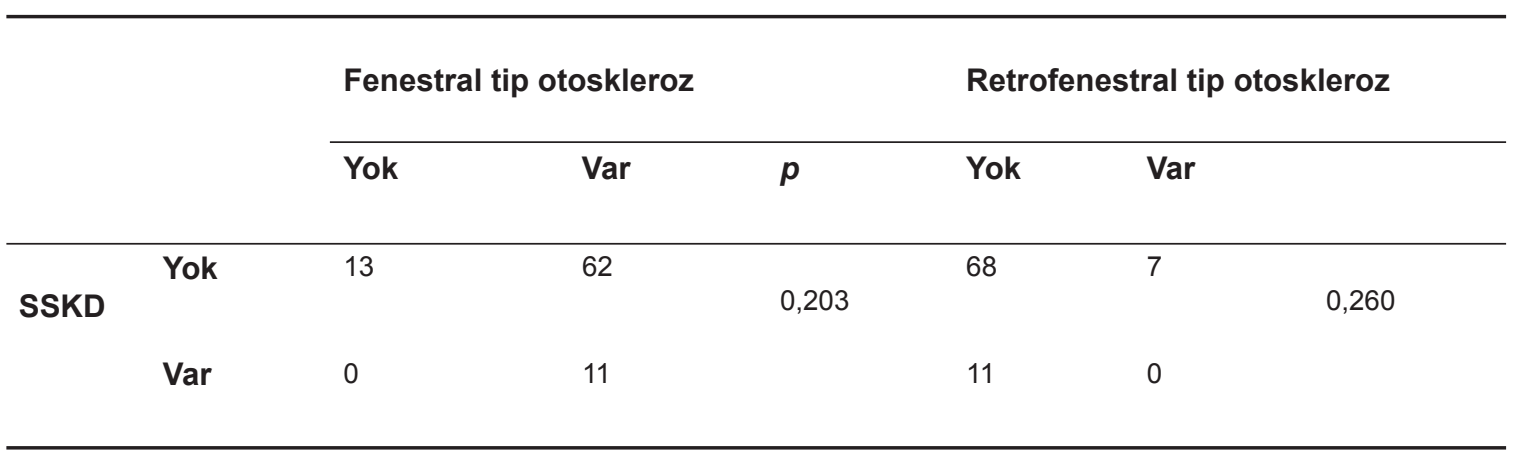

SSKD: Süperior semisirküler kanal dehissansı 


\section{Tartışma}

Otoskleroz fenestral ve retrofenestral olarak iki tipe ayrılmaktadır. Fenestral tip otoskleroz, fissula antefenestrumdaki oval pencerenin anteriorunda sınırlıdır ve bu hastalar iletim tipi işitme kaybı ile başvururlar. Bu tür hastaların tedavisi öncelikle stapedektomi ve protez yerleştirilmesidir. Retrofenestral (koklear) tip otoskleroz perilabirintin bölgede otosklerotik odaklarla karakterizedir. Bu tür hastalarda SNHL varsa, tedavide koklear implant kullanılabilir [7].

SSKD iç kulakta oval ve yuvarlak pencereye ek olarak 'üçüncü pencere' yaratır. Bu “üçüncü pencere" bazen düşük frekanslı iletim tipi işitme kaybına, vestibüler şikayetlere ve koklear hiperakuziye neden olabilir [9, 11-14]. SSKD ve otoskleroz bir arada olduğunda oval pencerede otoskleroza bağlı stapes fiksasayonu gelişir ve bunun sonucunda SSKD bulgularını maskeleyebilir. Otosklerozun cerrahi tedavisi ile oval pencere düzeyinde üçüncü bir pencere oluşturularak SSKD maskesi kaldırabilir. Bu da operasyon sonrası işitme ile ilgili bulguların düzelmesini engellemektedir. SSKD, iç kulağın en iyi belgelenmiş ve en çok araştırılan üçüncü pencere lezyonlarından biridir [15]. Bundan dolayı operasyon öncesi dönemde otoskleroz ve SSKD birlikteliğinin operasyon başarısı için tespiti gerekmektedir. Tanı için yüksek çözünürlüklü BT ve odyometri kombinasyonu önerilir [16]. Literatürde otoskleroz ve SSKD birlikteliğinin prevalansını gösteren kapsamlı bir çalışma bulunmamaktadır. Bu çalışmada otoskleroz ve SSKD sıklığı değerlendirildi.

Bu çalışmada temporal kemik BT'de otoskleroz bulgusu olan 43 hastanın Temporal kemik BT'si (86 temporal kemik) SSKD açısından değerlendirildi; 11 temporal kemikte $(\% 12,7)$ SSKD tespit edildi.

Literatürde Picavet ve ark.'nın [17] yapmış olduğu çalışmada klinik olarak otoskleroz tanısı olan 114 hastayı retrospektif olarak değerlendirmişler hastaların \%5,3'ünde (temporal kemiklerin \%6'sında) radyolojik olarak SSKD saptanmışlar, ancak bu çalışmada hastaların kaç tanesinde eşzamanlı otoskleroz ve SSKD olduğu belirsizdir ve klinik olarak otoskleroz tanısı almış hastaların kaçında otosklerozBT bulguları olduğutanımlanmamıştır. $\mathrm{Bu}$ çalışma da dahil olmak üzere önceki çalışmalarda, her iki durumu olan hastaların prevalansına ilişkin bilgi sağlamamaktadır. Bizim çalışmamızda tüm hastaların otoskleroz tanıları BT bulguları ile desteklenmiştir.

Berning ve ark.'nın [18] yapmış olduğu çalışmada vertigo, işitme kaybı, baş dönmesi ve kulak çınlaması bu çalışmada SSKD ile uyumlu semptomlar olarak kabul edilip 500 asemptomatik hastanın Temporal kemik BT tetkiklerini SSKD açısından değerlendirmişlerdir. 500 asemptomatik hastanın 10'unda (\%2), SSKD semptomu bulunan 110 hastanın 15'inde $(\% 13,6)$ radyolojik olarak SSKD tespit etmişler. Asemptomatik hastalara travma $(\% 77,6)$, kitle $(\% 9)$, enfeksiyon $(\% 6,6)$, ağrı $(\% 5,2)$, beyinomuriliksıvısıkaçağı(\%2,8), kranialsinirparalizisi $(\% 1)$, otoskleroz $(\% 0,8)$, preoperatif planlama $(\% 0,6)$, radyonekroz $(\% 0,4)$ endikasyonları ile temporal kemik BT görüntüleme yapılmıştır. Semptomatik hastaların kaçında otoskleroz nedeniyle görüntüleme yapıldığı bildirilmemiştir. Semptomatik hastaların oluşturduğu grubun SSKD prevalansı bizim sonucumuza daha yakındı.

Yine Altun ve ark.'nın [19] 129 hasta üzerinde yapmış olduğu bir çalışmada süperior semisirküler kanalı morfolojik olarak değerlendirmişler ve hastaların 27'sinde (\%11) SSKD tespit etmişlerdir. Duman ve Dogan [20] 1309 hastada yapmış oluduğu geniş kapsamlı bir çalışmada 2618 temporal kemik değerlendirilmiş bunların 262'sinde (\%10) SSKD bulunmuştur.

Ceylan ve ark.'nın [21] yaptığı 93 normal olarak rapore edilmiş hastanın temporal kemik BT'lerinin değerlendirilmesinde 186 temporal kemiği 23'ünde (\%12) SSKD rastlanmıştır. Williamson ve ark.'nın [22] yapmış olduğu çalışmada SSKD \%9 oranında tespit edildi.

Literatürdeki BT çalışmalarında SSKD sıklığı \%3-13 arasında değişmektedir [22-25]. Son yapılan çalışmalarda SSKD sıklığı, bu çalışmanın sonuçları ile benzerlik göstermektedir.

$\mathrm{Bu}$ çalışmanın kısıtlılıkları retrospektif olması, hasta sayısının azlığıdır. Bununla birlikte literatürde temporal kemik BT bulgusu pozitif otoskleroz prevalansına bakıldığında kabul edilebilir olmakla birlikte daha uzun süreli ve daha fazla hasta sayılı çalışmalara ihtiyaç duyulmaktadır. 
Sonuç olarak, otosklerozda SSKD'i \%12,7 sıklıkta gözlenmiş olup, yüksek çözünürlüklü temporal kemik BT ile SSKD, üçüncü pencere lezyonları ve eşlik eden diğer patolojilerin saptanması operasyonun klinik başarısını artıracaktır.

Çıkar ilişkisi: Yazar çıkar ilişkisi olmadığını beyan eder.

\section{Kaynaklar}

1. Valvassori GE. Imaging of otosclerosis. Otolaryngol Clin North Am 1993;26:359-371.

2. Koch $B$, Hamilton B, Hudgins $P$, Harnsberger $P$. Otosclerosis. In: Harnsberger HR ed. Diagnostic Imaging. Head and Neck, vol VI, 2nd ed. St. Amirsys: Manitoba, 2011;4-40.

3. Lee TC, Aviv RI, Chen JM, Nedzelski JM, Fox AJ, Symons SP. CT grading of otosclerosis. AJNR Am J Neuroradiol 2009;30:1435-1439. https://doi:10.3174/ ajnr.A1558

4. Merchant SN, Rosowski JJ, McKenna MJ. Superior semicircular canal dehiscence mimicking otosclerotic hearing loss. Adv Otorhinolaryngol 2007;65:137-145. https://doi:10.1159/000098790

5. Yamashita K, Hiwatashi A, Togao O, et al. Additive value of "otosclerosis-weighted" images for the CT diagnosis of fenestral otosclerosis. Acta Radiol 2017;58:12151221. https://doi: 10.1177/0284185116687172

6. Lagleyre S, Sorrentino T, Calmels $M N$, et al. Reliability of high-resolution CT scan in diagnosis of otosclerosis. Otol Neurotol 2009;30:1152-1159. https:// doi:10.1097/MAO.0b013e3181c2a084

7. Dudau C, Salim F, Jiang D, Connor SEJ. Diagnostic efficacy and therapeutic impact of computed tomography in the evaluation of clinically suspected otosclerosis. Eur Radiol 2017;27:1195-1201. https:// doi:10.1007/s00330-016-4446-8

8. Maxwell AK, Slattery WH 3rd, Gopen QS, Miller ME. Failure to close the gap: concomitant superior canal dehiscence in otosclerosis patients. Laryngoscope 2020;130:1023-1027. https://doi:10.1002/lary.28167

9. Mikulec AA, McKenna MJ, Ramsey MJ, et al. Superior semicircular canal dehiscence presenting as conductive hearing loss without vertigo. Otol Neurotol 2004;25:121-129. https://doi:10.1097/00129492200403000-00007

10. Minor LB, Carey JP, Cremer PD, Lustig LR, Streubel SO, Ruckenstein MJ. Dehiscence of bone overlying the superior canal as a cause of apparent conductive hearing loss. Otol Neurotol 2003;24:270-278. https:// doi:10.1097/00129492-200303000-00023
11. Merchant SN, Rosowski JJ. Conductive hearing loss caused by third-window lesions of the inner ear. Otol Neurotol 2008;29:282-289. https://doi:10.1097/ mao.0b013e318161ab24

12. MinorLB. Clinical manifestations of superior semicircular canal dehiscence. Laryngoscope 2005;115:1717-1727. https://doi:10.1097/01.mlg.0000178324.55729.b7

13. Masaki Y. The prevalence of superior canal dehiscence syndrome as assessed by temporal bone computed tomography imaging. Acta Otolaryngol 2011;131:258262. https://doi:10.3109/00016489.2010.526145

14. Lee YH, Rivas Rodriguez F, Song JJ, Yang KS, Mukherji SK. The prevalence of superior semicircular canal dehiscence in conductive and mixed hearing loss in the absence of other pathology using submillimetric temporal bone computed tomography. J Comput Assist Tomogr 2014;38:190-195. https://doi:10.1097/ RCT.0b013e3182ab2afb

15. Hope A, Fagan P. Latent superior canal dehiscence syndrome unmasked by stapedotomy for otosclerosis. J Laryngol Otol 2010;124:428-430. https://doi:10.1017/ S0022215109991654

16. Lehmann $M$, Ebmeyer J, Upile $T$, Sudhoff $\mathrm{HH}$. Superior canal dehiscence in a patient with three failed stapedectomy operations for otosclerosis: a case report. J Med Case Rep 2011;5:47. https:// doi:10.1186/1752-1947-5-47

17. Picavet V, Govaere E, Forton G. Superior semicircular canal dehiscence: prevalence in a population with clinical suspected otosclerosis-type hearing loss. B-ENT 2009;5:83-88.

18. Berning AW, Arani K, Branstetter BF. Prevalence of superior semicircular canal dehiscence on highresolution CT imaging in patients without vestibular or auditory abnormalities. AJNR Am J Neuroradiol 2019;40:709-712. https://doi:10.3174/ajnr.A5999

19. Altun O, Duman SB, Bayrakdar IS, Yasa Y, Duman S, Günen Yılmaz SG. Cone beam computed tomography imaging of superior semicircular canal morphology: a retrospective comparison of cleft lip/palate patients and normal controls. Acta Odontol Scand 2018;76:247-252. https://doi:10.1080/00016357.2017.1412498

20. Duman IS, Dogan SN. Contribution of reformatted multislice temporal computed tomography images in the planes of stenvers and pöschl to the diagnosis of superior semicircular canal dehiscence. J Comput Assist Tomogr 2020;44:53-58. https://doi:10.1097/ RCT.0000000000000957

21. Ceylan N, Bayraktaroglu S, Alper $\mathrm{H}$, et al. CT imaging of superior semicircular canal dehiscence: added value of reformatted images. Acta Oto-Laryngol 2010;130:9961001. https://doi:10.3109/00016481003602108 
22. Williamson RA, Vrabec JT, Coker NJ, Sandlin M. Coronal computed tomography prevalence of superior semicircular canal dehiscence. Otolaryngol Head Neck Surg 2003;129:481-489. https://doi:10.1016/s01945998(03)01391-3

23. Loke SC, Goh JPN. Incidence of semicircular canal dehiscence in Singapore. Br J Radiol 2009;82:371373. https://doi:10.1259/bjr/32471003

24. Branstetter BF 4th, Harrigal C, Escott EJ, Hirsch BE. Superior semicircular canal dehiscence: oblique reformatted CT images for diagnosis. Radiology 2006;238:938-942. https://doi:10.1148/ radiol. 2382042098

25. Cloutier JF, Bélair M, Saliba I. Superior semicircular canal dehiscence: positive predictive value of highresolution CT scanning. Eur Arch Otorhinolaryngol 2008;265:1455-1460. https://doi:10.1007/s00405-0080672-2

Etik kurul onayı: Bu çalışma Pamukkale Üniversitesi Tıp Fakültesi Etik Kurulu'nun 23.06.2020 tarih ve 37903 sayılı kararı ile onaylanmıştır. 